\title{
Three-dimensional Finite Element Analysis for Concrete Arch Dam of Tianshengqiao Reservoir
}

\author{
Liu Keding \\ Hunan Urban Construction College \\ Xiangtan, China \\ 297298755@qq.com
}

\begin{abstract}
The stress and strain of dam structure not only are the index of dam structure rigidity, but also are the basis of identifying whether the dam structural damage occur. Static analysis of dam is the foundation of design and construction of dam, includes the calculation and analysis of stress and strain of dam. The dam is a higher order statically indeterminate structure, and the variation of the temperature obviously affects the stress and displacement of the structure, therefore, it is very important to consider the randomness of the temperature change load in the static analysis of arch dam.Concrete arch dam is a common hydraulic structures. This article gives the stress and deformation distribution during construction and operation which has done the simulation analysis for concrete arch dam structure of Tianshengqiao Reservoir using the finite element method. The results show that Concrete Arch Dam Structure of Banjiang Reservoir satisfy the design requirements. Research for the design and construction of concrete singles arch dam provide some reference.
\end{abstract}

Keywords-Tianshengqiao reservoir ; Concrete arch dam; Finite element method; Simulation analysis, Operation period.

\section{ENGINEERING SITUATION}

Tianshengqiao Reservoir is located in Laliu River, Nandan County, Guangxi Zhuang Autonomous Region, which is a reservoir to generate electricity, combined with irrigation water resources and hydropower engineering[1]. Hub engineering is composed of dams, left bank gravity pier, shore spillway, water penstock, power plants, bottom outlet and other buildings. The total capacity of reservoir is 4.02 million $\mathrm{m}^{3}$, normal water level $24 \mathrm{~m}$, design water level $28.1 \mathrm{~m}$, check flood level $30.3 \mathrm{~m}[2]$.The dam is singles concrete arch dam, and the largest dam is $31.6 \mathrm{~m}$. The crest arc length is $43.44 \mathrm{~m}$, and the crest width is $1.2 \mathrm{~m}$. The dam bottom thickness is $1.7 \mathrm{~m}$, and the ratio of thickness to height is 0.37 .On the left of dam valley appear stepped. After setting up the gravity pier on the left bank, it becomes an ideal rectangle valley

\section{CAlculation Model}

\section{A Model Parameters}

Concrete arch dam structure of Tianshengqiao Reservoir uses concrete strength grade of $\mathrm{C} 15$, elastic modulus $E_{1}=22 \mathrm{GPa}$, poisson ratio $\mu_{1}=0.167$ [3-4], bulk density $\gamma_{1}=24 \mathrm{kN} / \mathrm{m}^{3}$. The rock of dam is permian Qixia limestone, medium thickness layer, hard lithology, basic integrity. Rock trend to upstream, and the karst of dam site is not developed, no leakage worries. Elastic modulus of rock is $E_{2}=12 \mathrm{GPa}$, and poisson ratio is $\mu_{2}=0.28$ [5].

\section{B Model Element}

Concrete arch dam and bedrock structure model uses isoparametric block element which has 8-node. The element is applied to three-dimensional model of the entity structure, have properties of plasticity, creep, swelling, stress stiffening, large deformation and large strain. The element has eight nodes and each node has three translational degrees of freedom[6-7] .

\section{Model Element}

The size of the entire calculation model is that it takes $90 \mathrm{~m}$ along the direction of the river, $75 \mathrm{~m}$ the direction of across the river, $76 \mathrm{~m}$ the vertical direction. The simulation range of model is $90 \mathrm{~m} \times 75 \mathrm{~m} \times 76 \mathrm{~m}$ (along the river $\times$ across the river $\times$ the vertical direction) [8]. The element division of arch and rock is shown in Fig .1. 


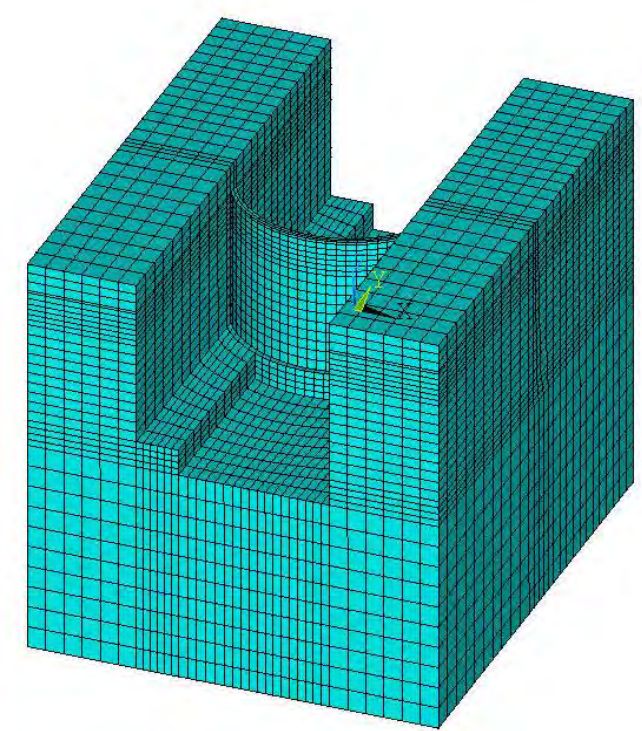

Figure 1. Arch and bedrock FEM division

\section{Calculation Condition}

Considering the mechanical characteristics of arch structure during operation[9], the following five cases are taken into account mainly: case1(structural weight and normal water level), case2(structural weight, design water level and tail water level), case3(structural weight, checking flood level and tail water level).

\section{ANALYSIS PATH}

While doing the finite element analysis of Tianshengqiao concrete arch dam, the analysis path is defined on the arch crown cross section and located

TABLE I. EACH CONDITION OF ARCH DAM SECTIONAL CROWN STRESS ON KEY POINTS（MPA）

\begin{tabular}{|c|c|c|c|c|c|c|c|c|}
\hline \multicolumn{2}{|c|}{ Location } & 1 & 2 & 3 & 4 & 5 & 6 & 7 \\
\hline \multirow{2}{*}{ case 1} & $\begin{array}{c}\text { Circumferential } \\
\text { stress }\end{array}$ & 0.386 & -0.418 & -1.513 & -1.229 & -0.425 & -0.070 & 0.034 \\
\hline & Vertical stress & 1.871 & 0.522 & -0.861 & -0.405 & 0.117 & 0.116 & 0.001 \\
\hline \multirow{2}{*}{ case 2} & $\begin{array}{c}\text { Circumferential } \\
\text { stress }\end{array}$ & 0.455 & -0.095 & -1.821 & -1.862 & -1.057 & -0.377 & 0.067 \\
\hline & Vertical stress & 1.850 & 1.089 & -0.981 & -0.583 & -0.092 & 0.056 & 0.001 \\
\hline \multirow{2}{*}{ case 3} & $\begin{array}{c}\text { Circumferential } \\
\text { stress }\end{array}$ & 0.559 & -0.513 & -2.219 & -2.226 & -1.452 & -0.736 & -0.137 \\
\hline & Vertical stress & 2.666 & 0.969 & -0.138 & -0.098 & -0.058 & -0.020 & 0.005 \\
\hline
\end{tabular}

As can be seen from Table 1, circumferential stress of arch crown's upstream face is stress normally, but vertical stress is tensile stress mainly. Especially at the junction of the bedrock and dam, tensile stress value is larger. This is mainly caused by the stress concentration. The larger upstream of the arch crown. We will select a calculation key point every $5 \mathrm{~m}$ from the bottom to the top of the dam.

\section{A Stress Analysis}

The circumferential and vertical stress has shown in tablelon the key points of concrete arch dam sectional crown. tensile stress value can be reduced by the equivalent stress finite element method [10].

The contour map of the first principal stress and circumferential stress can be seen in Fig .2 to Fig .7. 


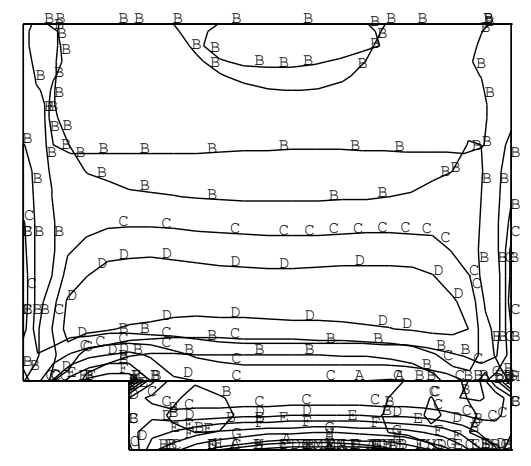

NODAL SOLUTION STEP $=$

SUB $=$

S1 (AVG)

$\mathrm{DMX}=.001968$

SMN $=-306738$

SMX $=.208 \mathrm{E}+07$

$=-174324$

$=90506$

$=355336$

$=884995$

$=.115 \mathrm{E}+07$

$. .194 \mathrm{E}+07$

Figure 2. Arch's contour map of first principal stress under case 1 ( $\mathrm{Pa})$

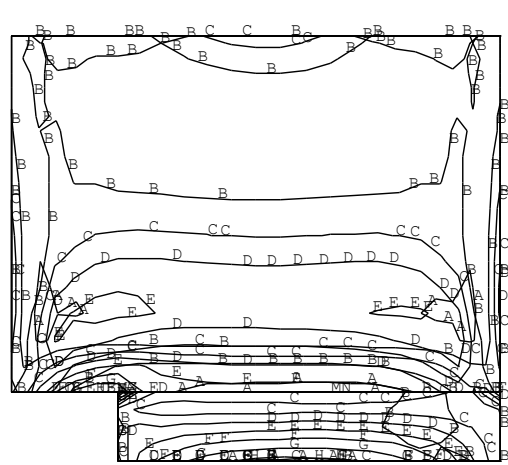

NODAL SOLUTION

STEP $=1$
SUB $=1$

TIME $=1$

S1 (AVG)

TOP

$\mathrm{DMX}=.002597$

$\mathrm{SMN}=-282353$

$\mathrm{MX}=.231 \mathrm{E}+07$

$=-138102$
$=150399$

$=150399$

$=438901$

$=727402$

$=.102 \mathrm{E}+07$

$=.130 \mathrm{E}+0$

$=.159 \mathrm{E}+07$

$=.188 \mathrm{E}+0$

$=.217 \mathrm{E}+0$

Figure 4. Arch's contour map of first principal stress under case 2( $\mathrm{Pa})$

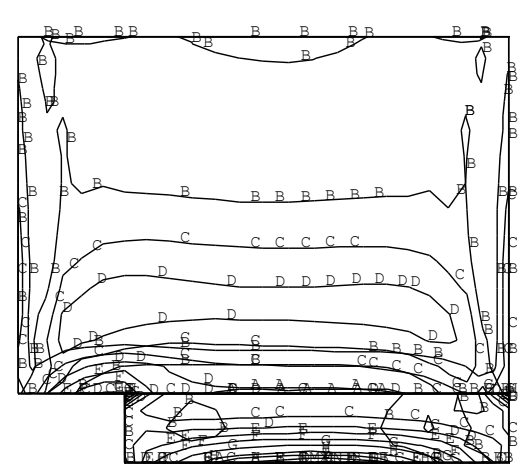

NODAL SOLUTION

$\operatorname{STEP}=1$

SUB $=1$

TTME $=1$

S1

(AVG)

$\mathrm{DMX}=.003232$

$\begin{array}{ll}\text { DMX } & =.003232 \\ \text { SMN }=-402559\end{array}$

SMN $=-402559$
SMX $=.294 \mathrm{E}+07$

SMX $=.294 \mathrm{E}+07$

$=-217129$
$=153729$

$=524588$

$=895446$

$=.127 \mathrm{E}+07$

$=.164 \mathrm{E}+07$

$=.201 \mathrm{E}+07$

$=.238 \mathrm{E}+07$

$=.275 \mathrm{E}+07$

Figure 6. Arch's contour map of first principal stress under case $3(\mathrm{~Pa})$

From Fig .2, Fig .4 and Fig .6 it can be seen, arch contour maps of the first principal stress are similar, and the maximum principal tensile stresses appear at the junction of the bedrock and the dam。 The first primary stress also significantly increased with the rise of water level, and the distribution range of the main tensile stress also increases. From Fig .3, Fig .5 and Fig .7 can be seen, the circumferential stress of the arch is stress mainly, and the stress distribution is very complex. But in the bottom of the arch emerges a range of tensile stress, and its value is not high.

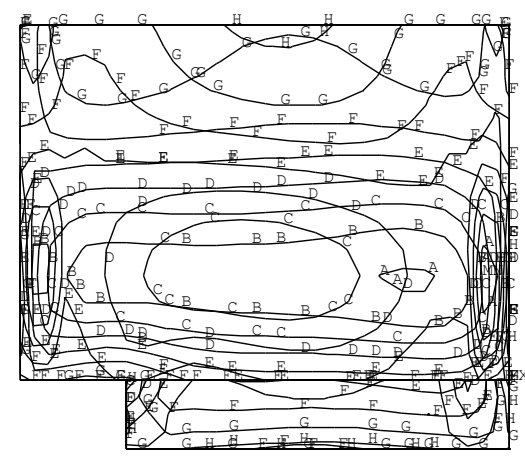

NODAL SOLUTION

$\mathrm{STEP}=1$

SUB $=1$

TIME $=1$

SY

(AVG)

RSYS $=15$

DMX $=.001968$

SMN $=-.182 \mathrm{E}+0$

SMX $=698701$

$=-.168 \mathrm{E}+07$

$=-.112 \mathrm{E}+07$
$=-839361$

$=-559713$

$=-280066$

$=-418.234$

$=279229$

Figure 3. Arch's contour map of circumferential stress under case 1

( $\mathrm{Pa})$

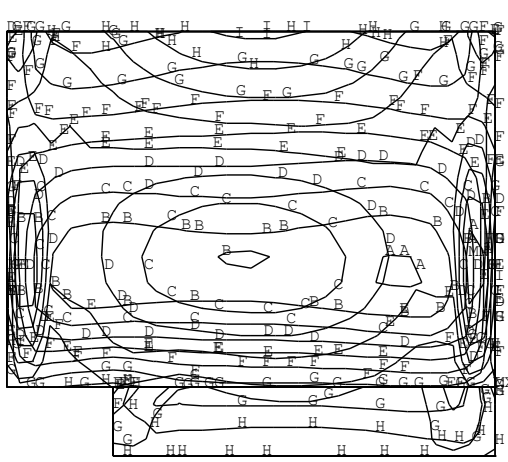

NODAL SOLUTION

$\mathrm{STEP}=1$

SUB $=$

SY (AVG)

RSYS $=15$

$\mathrm{DMX}=.002597$

SMN $=-.239 \mathrm{E}+07$

SMX $=649867$

$\begin{aligned} & =-.222 \mathrm{E}+07 \\ & =-.189 \mathrm{E}+07\end{aligned}$

$=-.155 \mathrm{E}+07$

$=-.121 \mathrm{E}+07$

$=-871870$

$=-533707$

$=-19554$

$=142621$

$=480785$

Figure 5. Arch's contour map of circumferential stress under case 2 ( $\mathrm{Pa})$

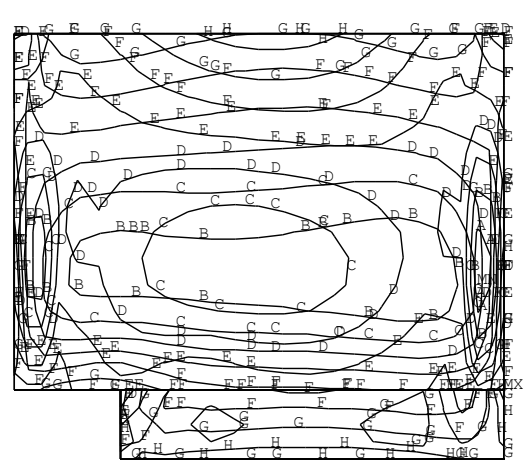

NODAL SOLUTTON

$\mathrm{STEP}=1$

SUB $=$

TIME $=1$

$\mathrm{SY}$

TOP

RSYS $=15$

DMX $=.003232$

$\mathrm{SMN}=-.290 \mathrm{E}+07$

SMX $=914744$

$=-.268 \mathrm{E}+07$

$=-.226 \mathrm{E}+07$

$=-.184 \mathrm{E}+07$
$=-.141 \mathrm{E}+0$

$=-990636$

$=-567218$

$=-143800$

$=279618$

$=703035$

Figure 7. Arch's contour map of circumferential stress under case 3

( $\mathrm{Pa})$

\section{B Deformation Analysis}

By deformation analysis of Tianshengqiao Reservoir, we calculate the radial displacement value on the key points of Arch Dam sectional crown, and its results of stress are shown in table 2. For case 2 the arch contour of displacement is shown in Fig .8 and Fig .9. 
TABLE 2. EACH CONDITION OF ARCH DAM SECTIONAL CROWN RADIAL DISPLACEMENT ON KEY POINTS（MM）

\begin{tabular}{|c|c|c|c|c|c|c|c|}
\hline Location & $\mathbf{1}$ & $\mathbf{2}$ & $\mathbf{3}$ & $\mathbf{4}$ & $\mathbf{5}$ & $\mathbf{6}$ & $\mathbf{7}$ \\
\hline case1 & 0.160 & 0.766 & 1.785 & 1.638 & 0.869 & 0.443 & 0.306 \\
\hline case2 & 0.057 & 0.579 & 2.177 & 2.446 & 1.734 & 1.049 & 0.640 \\
\hline case3 & 0.222 & 1.087 & 2.774 & 3.055 & 2.383 & 1.673 & 1.159 \\
\hline
\end{tabular}

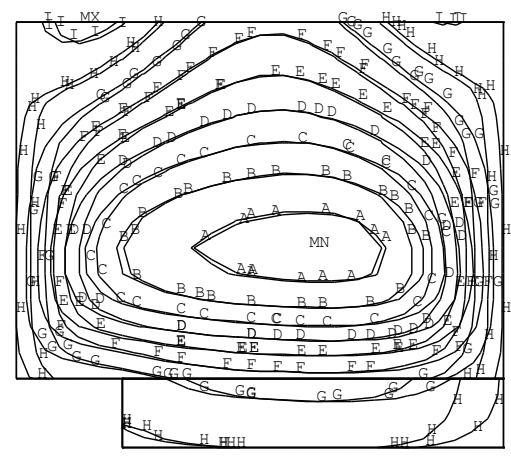

NODAL SOLUTION
STEP $=1$
SUB $=1$
TIME $=1$
UX
TOP
RSYS $=15$
DMX $=.002597$
SMN $=-.002595$
SMX $=.455 \mathrm{E}-03$
A $=-.002425$
B $=-.002086$
C $=-.001747$
D $=-.001409$
E $=-.00107$
F $=-.731 \mathrm{E}-03$
G $=-.392 \mathrm{E}-03$
H $=-.532 \mathrm{E}-04$
I $=.286 \mathrm{E}-03$

Figure 8. Arch's contour map of radial displacement under case 2(m)

From Table 2 and Fig .8 and Fig .9 can be seen that with the increase of the water level, the radial displacement significantly increased on the key points of Arch Dam sectional crown, but the biggest radial displacement appear in the middle of the arch crown, while the radial displacement is small at the top and bottom of the arch crown. For arch dam the value of radial displacement is larger than the value of vertical displacement, and the largest vertical displacement appears in the top of the arch crown.

\section{CONCLUDING REMARKS}

In summary, using concrete arch dam scheme of Banjiang reservoir is reasonable. Basically, circumferential stress of arch dam upstream face is compressive stress. Furthermore, the arch's first principal stress which is small can meet the strength requirements, so the structure is safe and reliable.

\section{REFERENCES}

[1] Bans Sevim,Ahmet Can Altunisik,Alemdar Bayraktar et al. Estimation of Elasticity Modulus of a Prototype Arch Dam Using Experiments" Methods [J]. Journal of Materials in Civil Engineering,2012,24(4):321-329.
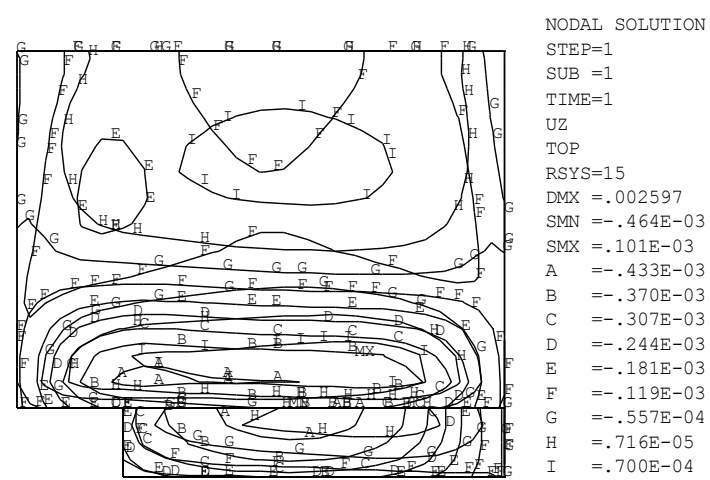

Figure 9. Arch's contour map of vertical displacement under case 2 (m)

[2] Bans Sevim,Ahmet Can Altunisik,Alemdar Bayraktar et al. Earthquake Behavior of Berke Arch Dam Using Ambient Vibration Test Results [J]. Journal of Performance of Constructed Facilities,2012,26(6):780-792.

[3] SL191-2008. Design Code for Hydraulic Concrete Structure[S] China Water Conservancy and Hydropower Press, 2008.

[4] Li Shouyi,Ding Lujun,Zhao Lijuan et al. Optimization design of arch dam shape with modified complex method [J]. Advances in Engineering Software,2009,40(9):804-808.

[5] Seyed Mohammad Seyedpoor,Javad Salajegheh,Eysa Salajegheh et al. Shape optimal design of materially nonlinear arch dams including dam-water-foundation rock interaction using an improved PSO algorithm [J]. Optimization and engineering,2012,13(1):79-100.

[6] Xucheng Wang. Finite Element Method [M]. Tsinghua University Press, 2003.

[7] Bofang Zhu. Finite Element Method Principle and Application [M]. China Water Conservancy and Hydropower Press, 1998.

[8] Bans Sevim,Alemdar Bayraktar,Ahmet Can Altunisik et al. Investigation of water length effects on the modal behavior of a prototype arch dam using operational and analytical modal $\begin{array}{llll}\text { analyses } & {[\mathrm{J}] \text {. Structural engineering and }}\end{array}$ mechanics,2011,37(6):593-615.

[9] SL282-2003. Design Code for Concrete Arch Dam [S]. China Water Conservancy and Hydropower Press, 2003.

[10] Bofang Zhu, Jizhang Gao, Zuyu Chen, Yisheng Li. Arch Dam Design and Research [M]. China Water Conservancy and Hydropower Press, 2002. 